\title{
Thaumatomyrmex strips millipedes for prey: a novel predatory behaviour in ants, and the first case of sympatry in the genus (Hymenoptera: Formicidae)
}

\author{
C. R. F. Brandão ${ }^{1}$, J. L. M. Diniz ${ }^{1}$ and E. M. Tomotake ${ }^{2}$ \\ 1 Museu de Zoologia da Universidade de São Paulo, C.P. 7172; São Paulo, SP, 01064, Brazil \\ ${ }^{2}$ Dept. Biologia, IB, Universidade Estadual Paulista "Júlio de Mesquita Filho", C. P. 178; Rio Claro, \\ SP, 13500, Brazil
}

Key words: Thaumatomyrmex, taxonomy, comparative morphology, predation, Polyxenidae.

\section{Summary}

We describe, for the first time, the predatory behaviour of Thaumatomyrmex ants on millipedes of the family Polyxenidae, based on field observations of T. atrox and a field and laboratory study of T. contumax. The capture of the prey and the removal process of its body-covering setae by the ants before they eat the millipede are described. This specialized behaviour in at least two species of the genus, belonging to two distinct groups of species, indicates a general trend in Thaumatomyrmex. We coupled this study with a comparative morphological analysis of the mouthparts and digestive tube of these and other Thaumatomyrmex species. Also, we report the first case of sympatry in the genus, which suggests that Thaumatomyrmex includes several species, and not only one highly variable taxon, as hypothetized earlier.

\section{Introduction}

The exclusively Neotropical ant genus Thaumatomyrmex is characterized by its long, bizarre, slightly asymmetric, pitchforked mandibles, with three or four long and slender inner teeth, whose tips may project beyond the genae when the mandibles are closed. Also, the retracted clypeus is not common for a ponerine, suggesting a high degree of specialization in the use of these structures, possibly also related to specialized feeding habits.

The habits of Thaumatomyrmex ants are virtually unknown. These seldomcollected ants are represented in museums by less than one hundred specimens. The only information available is that of Kempf (1975), who writes 'The peculiar mandibles mark these ants as predators, but we have no positive knowledge of their prey and preferences. The closest indication, yet no explicit proof, lies in the fact that mutilatus was found on two occasions in intimate association with termites. However, their feeding on termites, which seems highly probable, was not observed. 
A previous hypothesis of their being snail eaters, based on the fact that the holotype of cochlearis was accidentally discovered in a collection of empty shells of land snails with which the ground was literally carpeted, seems flimsy and far-fetched'.

Diniz and Brandão (1988) published a small note on the feeding habits of Thaumatomyrmex. In the present paper, we describe for the first time details of the highly specific predatory habit of T. contumax on polyxenid millipedes. Also, we describe our recent observations of the same habit shown by T.atrox in field conditions. In an attempt to elucidate better the adaptations related to this predatory life-form, we studied the comparative morphology of the mouthparts and digestive tube of three Thaumatomyrmex species: T. atrox, T. mutilatus, and T. contumax.

Thaumatomyrmex was revised by Kempf (1975), who recognized eight species. Longino (1988) recently re-studied the ferox species group, showing that the differences in relative lengths of metric characters might not reflect species differences. In addition, the presence and distinctness of the metanotal impression are size-related, and thus not an adequate diagnostic character for distinguishing Thaumatomyrmex species. Accordingly, Longino (op. cit.) proposed the synonymy of T. manni and T. zeteki with T. atrox, and T. paludis and Thaumatomyrmex sp. Kempf with $T$. ferox. Furthermore, he suggested that the genus may include only one highly variable species, composed of morphologically differentiated allopatric populations.

We discuss Longino's (op. cit.) hypothesis outlined above, based on fresh material collected by us, including the first case of sympatry in the genus.

\section{Predatory behaviour of Thaumatomyrmex}

\section{A. T. contumax}

One of us (JLMD) collected on 25 November 1988, in an old cocoa field reserve at $\mathrm{km} 22$ of the Itabuna and Ilhéus road, state of Bahia, Brazil $\left(14^{\circ} 49^{\prime} \mathrm{S}, 39^{\circ} 12^{\prime} \mathrm{W}\right)$, a worker of $T$. contumax, apparently returning to the nest with a small unidentified non-calcareous polyxenid millipede firmly attached between the mandibles. When the ant was followed, a small colony, or part of it, was found at the base of a fallen dry bromeliad leaf, along with a colony of Strumigenys (Dacetini). The population consisted of three mature workers, a recently emerged male, two pupae and three larvae in different stages. When the leaves were parted, the workers feigned death for many minutes, and only the male remained near the brood. No other colonies were found in neighbouring bromeliads.

The colony was brought to São Paulo in a glass tube and transferred to an artificial ceramic nest composed by a foraging arena $(15 \times 15 \mathrm{~cm})$, connected by a short tunnel to a small covered chamber $(2 \times 5 \mathrm{~cm})$. In a few hours the workers found the chamber, to which they transferred the immatures. Workers did not transport other workers. The larvae spun cocoons and emerged from them without apparent aid, already with the dark colour of older individuals. Juveniles remained in the colony chamber for three to four days prior to foraging outside the chamber. The eggs laid by the workers 
while the colony was under observation were kept in groups of two or three scattered on the ground.

Several food items were offered at the foraging arena, after a starvation period of five days (termite workers (mostly Procornitermes); fly and beetle larvae; alive, dead or injured Collembola; Bhatkar \& Whitcomb artificial diet for ants; Archeognatha; sardine; honey/water and Diplopoda Polyxenidae), but only millipedes were captured and transported to the nest chamber. Polyxenids are extremely abundant in Neotropical litter, though their predators are not known. This represents also the first report of an ant specialized on preying polyxenids [see revison in Hölldobler and Wilson (1990)]. Thaumatomyrmex belongs to the group of specialized predator ant genera whose workers forage singly, feigning death when disturbed.

Before eating the prey tissues the ant completely divests the millipede from its abundant hairs, in a very characteristic manner, that we were able to follow several times. These observations are described below in three phases:

1. Prey searching, recognition and stinging. Workers forage individually, often in different places of the arena at the same time. In the field they also leave the nest singly. They apparently do not recruit nestmates in any sense or circumstance, even when we offered more than one millipede at a time. This is possibly related to the solitary habits of the prey. In the laboratory, ants actively search for prey, apparently using olfactory stimuli. The prey is first inspected and seized with the antennae (Fig. 1), then snapped with the mandibles, stung at the intersegmental membranes (Fig. 2), and rapidly brought to the colony chamber. In all events a full contact of the ants with the millipedes and their unpalatable hairs does not occur. The prey's abundant, long and stiff setae are not firmly attached to the integument. When the millipedes were being held by the ants, tufts of setae could be seen falling from their bodies, as illustrated in Figure 2.

2. Stripping the prey: In the chamber, the paralysed prey is laid on the ground, carefully held again between the mandibles, with the ant's inner teeth barely touching the prey integument. The millipede is then turned ventral side up, and has all of its setae torn out by means of the ant's fore tarsi, which bear small but stout setae on the ventral face. The worker thrusts the prey back and forth within its mandibles, until the millipede is completely divested from its setae covering (Fig. 3). The cleaning sequence lasts for as long as 20 minutes, and is interrupted many times for the ant's complete autogrooming. This suggests that the millipedes may produce a repulsive or irritating substance, which is probably associated to the setae. When still bearing setae the prey is kept away from the ant's mouth parts and from the colony immatures. Perhaps the ant's retracted clypeus and sclerotized labrum are also adapted to this specific predatory habit. The efficiency and swiftness of the ant's venom may prevent the still 'uncleaned' millipede from struggling and touching the ant.

We observed several instances where the workers, using their forelegs, carried away from the nest chamber abandoned tufts of polyxenid setae; this procedure, however, is not totally efficient. This fact supports the notion that the aversive substance produced by the prey may be concentrated in the hairs. In fact, preying on 


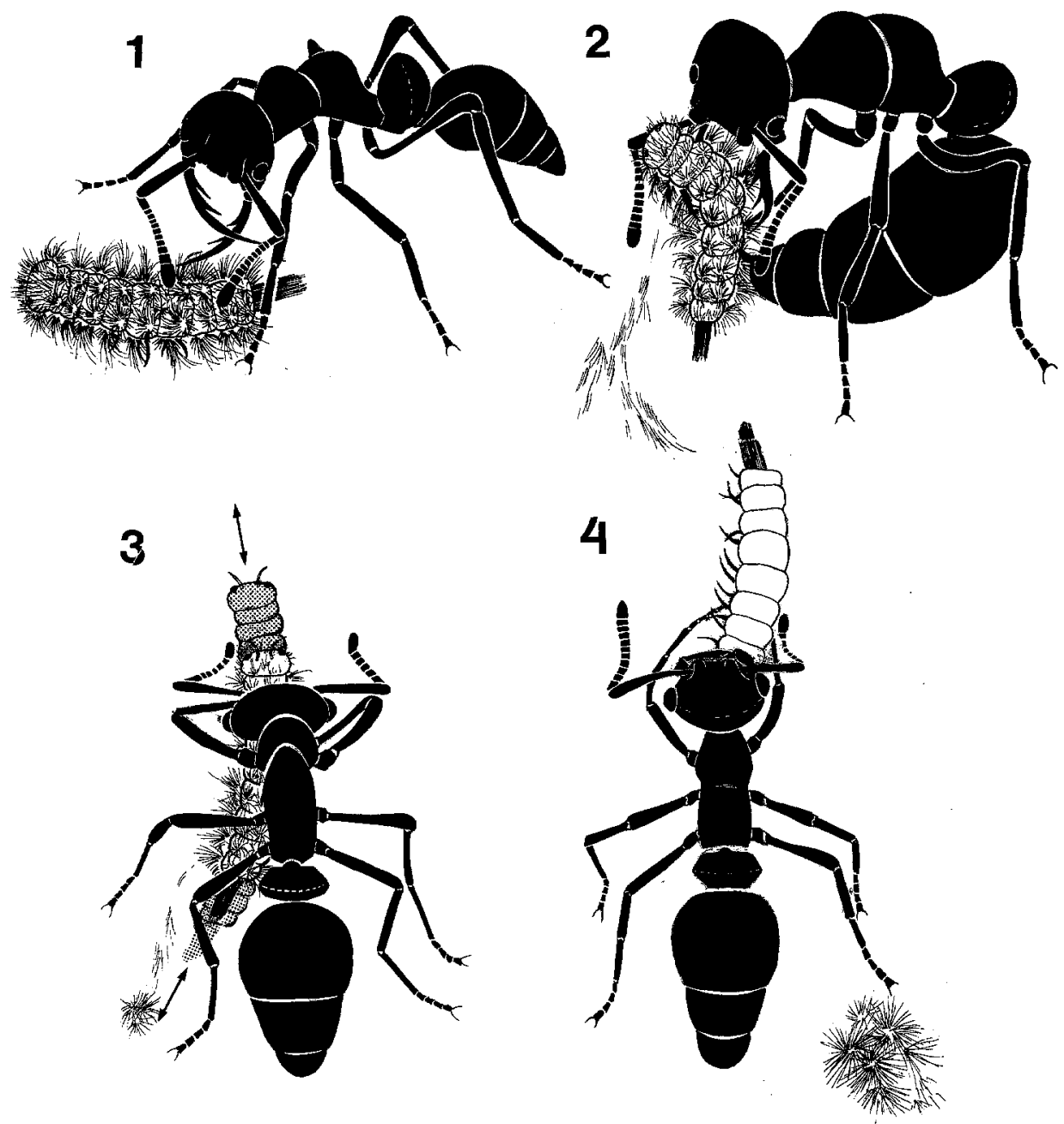

Figures 1-4. Worker of T. contumax preying on millipede polyxenid (based on photographs): 1 -inspecting and seizing millipede prey; 2 - stinging prey (note millipede's setae falling from its body); 3 - stripping the millipede from its upalatable setae (arrows indicate back-and-forth movements of the prey); 4 -eating prey's tissues, starting from the head (note the prey's tuft of setae at the left of the figure and the posterior tuft, which in this case was not torn out before the ant started to eat)

Polyxenidae is very uncommon for ants and other animals as well, and the unpalatable setae covering may be regarded as an effective anti-predator strategy. Millipedes are known to produce quinones in lateral segmental glands (Monro et al., 1962), thought to act as effective defences.

After the treatment the prey is devoid of setae, but its integument is totally preserved, as can be seen in Fig. 5 . We did not notice any wound, even with higher magnifications of the stereoscope. 


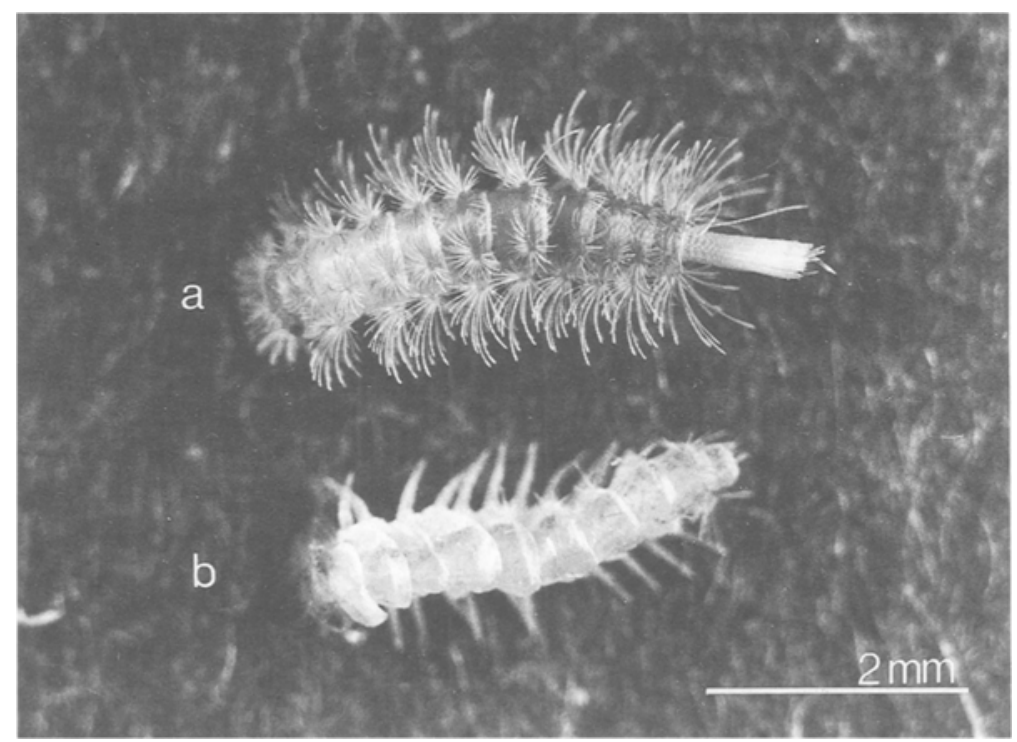

Figure 5. Polyxenidae before and after 'treatment' by a T. contumax worker. a) untouched millipede. b) millipede after full strip (note that in this particular case the posterior tuft of setae has been completely removed by the ant)

3. Feeding: The workers eat most of the prey tissues, starting from the head (Figs. 4, 6); only the remains are laid out to the ant's larvae for feeding. We did not mark the ants individually, but it seems that each ant devours the prey it captured. Sometimes, however, the prey is shared with other workers, though we never saw a millipede being dismembered. When sharing, each ant concentrates on one end of the prey, with the collector ant usually feeding off the anterior portion. We observed several occasions when soliciting workers stayed beside a cleaning ant, touching it with very fast movements of the antennae for periods of two seconds, interrupted by inactive periods of one second. The ingestion of the prey may take up to 30 minutes.

\section{B. T. atrox}

In November 1990, Diniz and Brandão collected two individuals of T. atrox at a dry forest ('mata-de-cipó) in Central Bahia, Brazil (Fazenda Maria Inácia, Maracás, $13^{\circ} 26^{\prime} \mathrm{S}, 40^{\circ} 27^{\prime} \mathrm{W}$ ), one of them carrying a small polyxenid between the mandibles, in the same manner described above for $T$. contumax. Our attempts to locate the colony failed, as the substrate was extremely complex. We were able to confirm, however, that at least two species, belonging to different groups of species, prey on polyxenids in field conditions.

\section{Morphology}

We studied the mouth parts and digestive tube of T.atrox, T. contumax, and T. mutilatus. In Fig. 7 we present the head in frontal view of a worker of T. contumax 


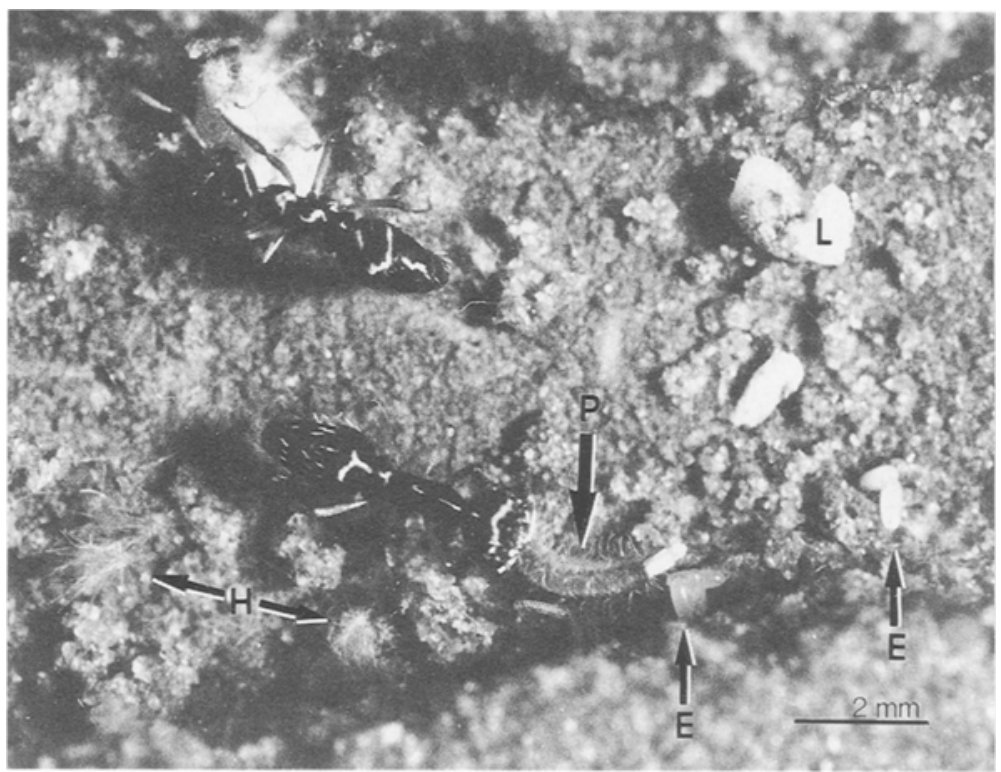

Figure 6. Worker of T. contumax with partially denuded Polyxenidae prey (P), corresponding to Fig. 4, (E) group of eggs, $(\mathrm{H})$ tufts of millipede setae, (L) dead larvae

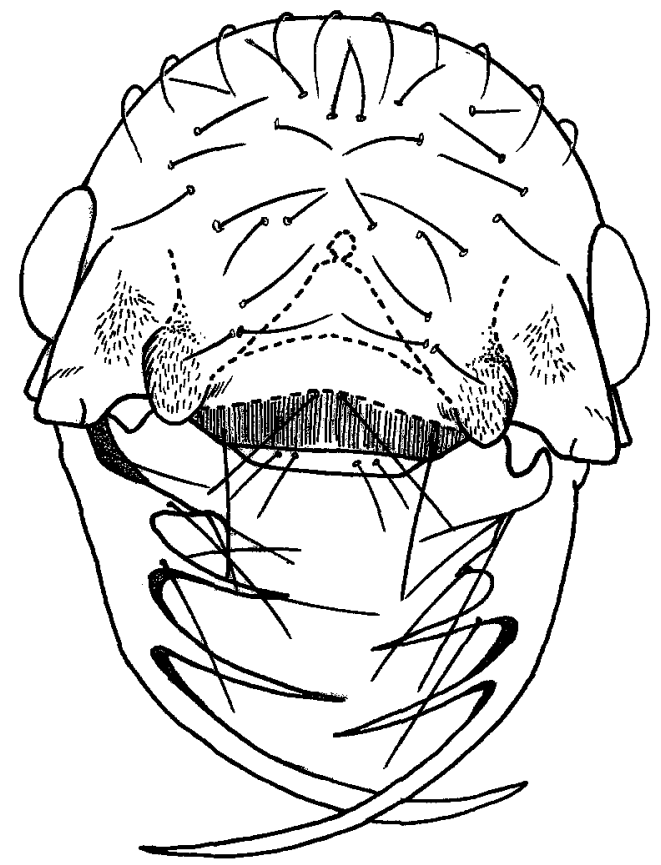

Figure 7. Head, in frontal view, of a T. contumax worker (antennae omitted). Head width (across compound eyes) $=1.04 \mathrm{~mm}$ 


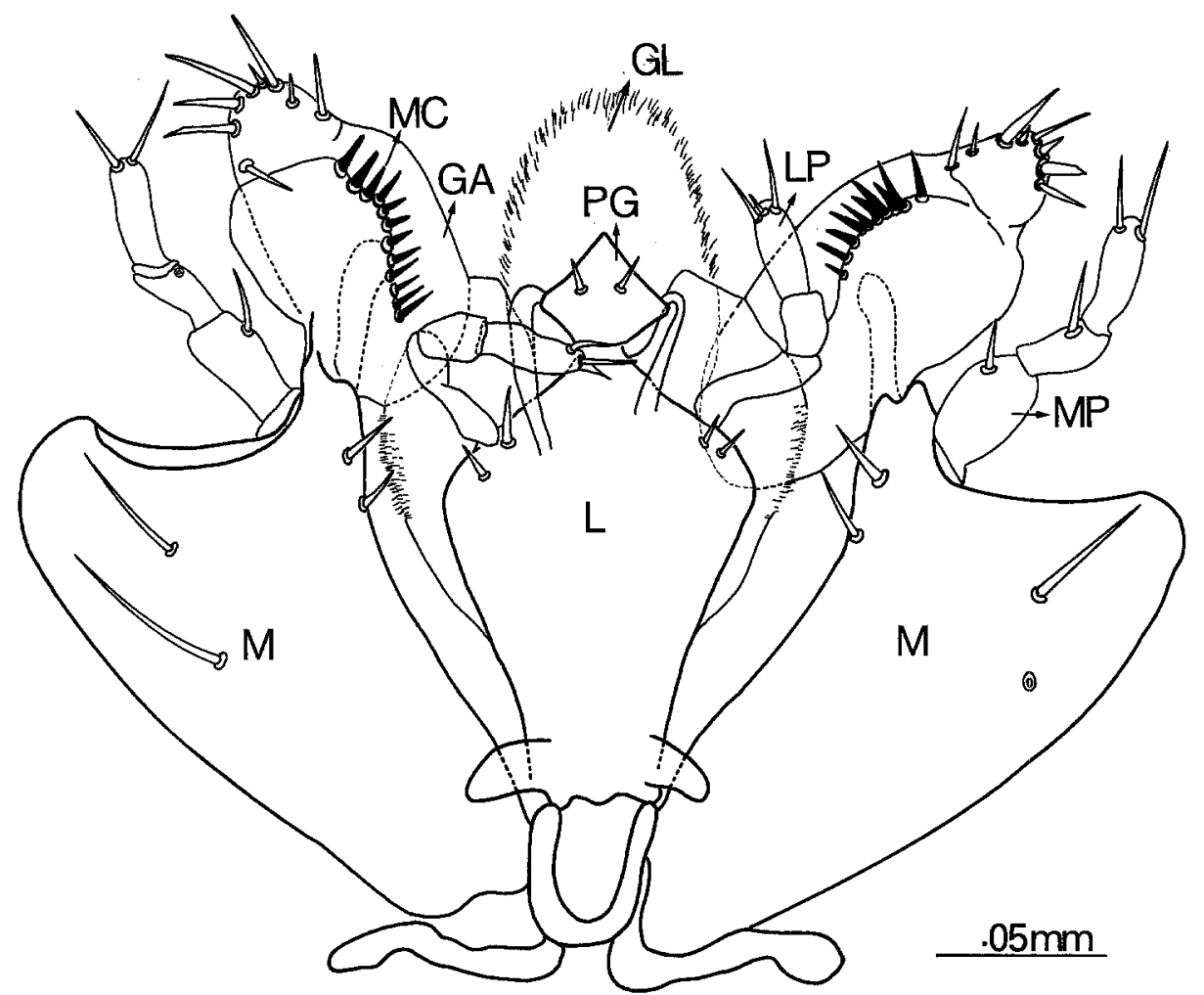

Figure 8. Mouth parts of T. atrox in ventral view. Note that the maxillary comb (MC) has been drawn as seen through the transparent galea (GA); only the outer borders of the glossae (GL) have been illustrated. (L) labium, (M) maxilla, (LP) labial palpus, (MP) mxillary palpus, (PG) paraglossae

from Ilhéus, showing the asymmetric mandibles and sculpturing pattern. Stray workers of T. mutilatus were found on the campus grounds in Rio Claro, SP, Brazil $\left(22^{\circ} 24^{\prime} \mathrm{S}, 47^{\circ} 33^{\prime} \mathrm{W}\right)$, while isolated T. atrox workers were captured at the same site in Ilhéus where we collected T. contumax.

Although Kempf (1978) cited the palpi counts of T.paludis (=T. ferox) as 3:2, we found $3: 3$ in the species we examined. The mouth parts of all species are very similar to the one depicted in Fig. 8, taken from the same individual as Fig. 7. The only difference is in terms of the number of setae: at the stipes, $T$. mutilatus has three pairs instead of two, while the fused lozenge-shaped paraglossae bear two pairs instead of one. The mouth apparatus of $T$. atrox could not be differentiated from the one we illustrate. Unfortunately, there is no comparative study on the holomorphology of the Ponerinae mouth parts. Comparing Thaumatomyrmex mouth parts with those of Amblyopone pallipes (Gotwald, 1969), the former is derived in many characters, e.g. palpi counts and the peculiarly-shaped paraglossae.

T. atrox, T. mutilatus, and T. contumax have respectively 4,8 , and 10 Malpighian tubules attached to the digestive tube (Fig. 9). The pattern of rectal pads and the simple proventricular bulb are very much alike in all studied species. A study 


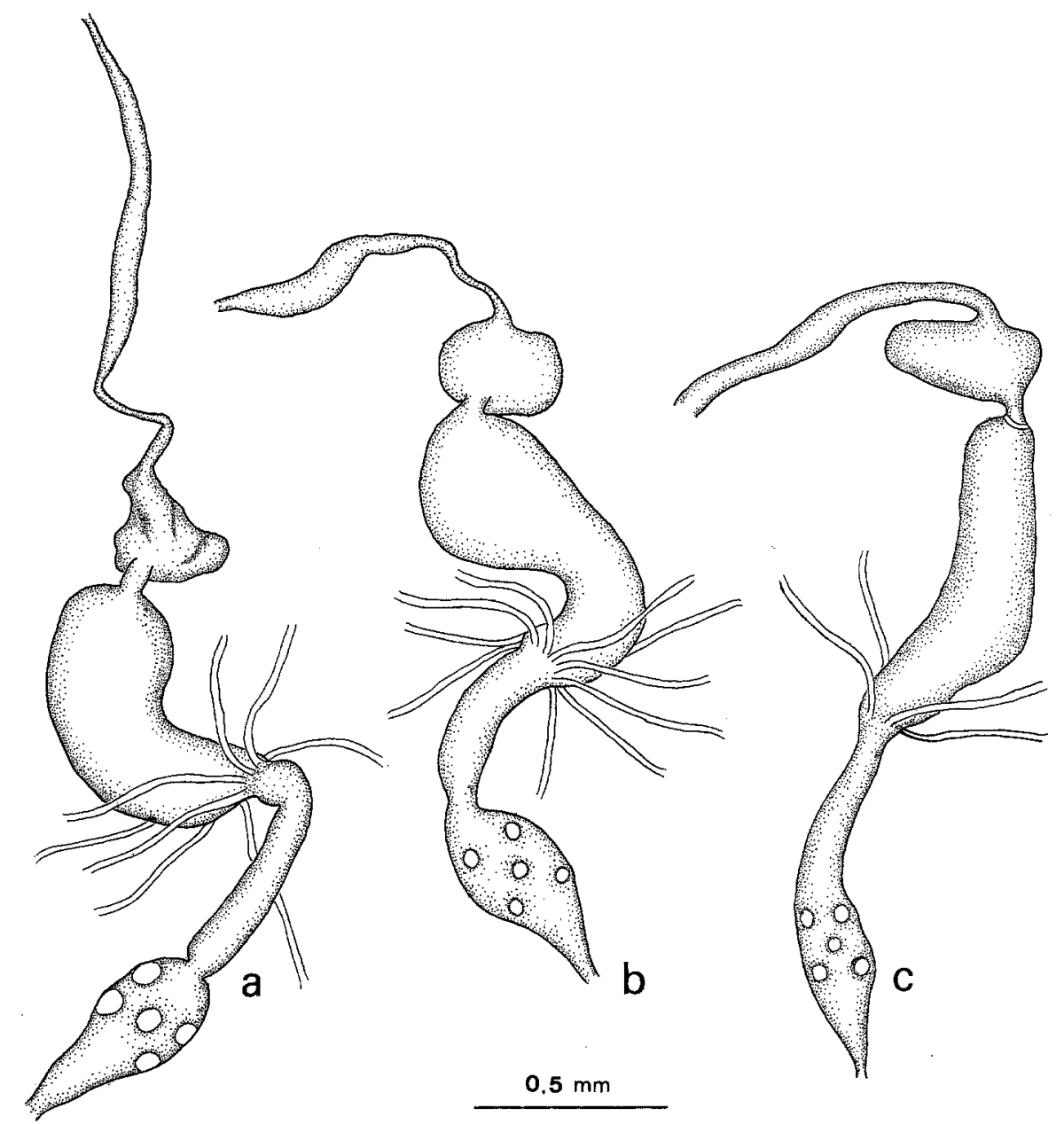

Figure 9. Digestive tubes of Thaumatomymex species:

a $-T$. mutilatus (mutilatus group)

$\mathrm{b}-T$. contumax (multilatus group)

c - T. atrox (ferox group)

on the homology of Ponerinae digestive tube regions is in preparation (Tomotake, 1991).

In short, the pitch-forked mandibles and retracted clypeus are the only clearcut characters we identified in the studied traits that could be easily related to the predatory habit of Thaumatomyrmex.

\section{Taxonomy}

The collection of four nestmates of $T$. contumax represents the first opportunity to study intranidal variation, in order to compare with Longino's (1988) study of 
museum specimens found isolated in many localities. Using the same procedures as his, we plotted the same measurements, confirming an apparent uniform allometric variation. The points fall within the same straight line he found for the ferox group. The workers' Malpighian tubule counts and details of the mouth apparatus are different, however, from those of other Thaumatomyrmex species, including those of T. mutilatus - the other member of the mutilatus group.

The largest workers are even slightly larger than the T. contumax holotype (only known specimen of this taxon until now), but we agree, however, with the differential characters and indices presented by Kempf (1975) to distinguish species within the mutilatus group. The later author also argued that $T$. contumax could be a member of a 'geographic race' or the end of a continuous morphocline of T. mutilatus. Based on the information presented herein, we prefer to regard them as different species.

Six workers of a Thaumatomyrmex species (ferox group) were collected by Jacques Delabie and Jorge L. M. Diniz from soil samples or under leaves in the same locality where T. contumax was found (Ilhéus). Accepting Longino's (1988) interpretation, we recognize them as $T$. atrox, by the presence of a conspicuous basal tooth on the mandibles. The specimens show the smallest values of head width for all known Thaumatomyrmex, ranging from 0.53 to $0.55 \mathrm{~mm}$. The T. atrox workers from Maracás are similar in every detail to those from Ilhéus.

The presence of at least two easily recognizable Thaumatomyrmex species in the same cocoa field in Ilhéus represents the first case of sympatry in the genus. This strongly supports the notion that Thaumatomyrmex is not mono-specific, composed by a set of morphologically differentiated allopatric populations, as hypothetized by Longino (1988). This suggests that the genus may include several, at least five, rarely collected species.

\section{Acknowledgements}

We would like to thank Jacques Delabie for allowing us to study his precious ant collection from Eastern Brazil, and also for his and Tereza Delabie's hospitality during our visit to Itabuna and Ilhéus. Sérvio T.P. Amarante, Johan Billen, Eliana Cancello, Norma Gomes, Miriam Marques, Paulo Oliveira, and P. E. Vanzolini helped us in many ways. We are indebted to CEPLAC and its staff for the help at the field station. FAPESP, CNPq, and CAPES supported this work.

\section{References}

Diniz, J. L. M. and C. R. F. Brandão, 1989. Feeding behavior of Thaumatomyrmex. Notes from Underground 2:13.

Gotwald Jr., W. H., 1969. Comparative morphological studies of the ants, with particular reference to the mouthparts (Hymenoptera: Formicidae). Mem. Cornell Univ. agric. Exp. Stn. 408:1-150.

Hölldobler, B. and E. O. Wilson, 1990. The Ants. Belknap Press of the Harvard Univ. Press, Cambridge, $732 \mathrm{pp}$.

Kempf, W. W., 1975. A revision of the neotropical ponerine ant genus Thaumatomyrmex Mayr (Hym. Formicidae). Studia ent. 18:95-126.

Longino, J. T., 1988. Notes on the taxonomy of the Neotropical Ant Genus Thaumatomyrmex (Hymenoptera: Formicidae). In: Advances in Myrmecology (J.C. Trager, ed.), E. J. Brill and W. S. Heinman Co., Inc., NY, p. 35-42. 
Monro, A., M. Chadha, J. Meinwald, and T. Eisner, 1962. Defense mechanisms of Arthropods. VI. Para-benzoquinones in the secretion of five species of millipedes. Ann. ent. Soc. Am. 55:261-262. Tomotake, M. E. M., 1991. Morfologia comparada do Trato digestivo de Formigas de quatro Tribos da Subfamilia Ponerinae (Hymenoptera: Formicidae). MsC Dissertation, IB-UNESP, Rio Claro, Brazil, 112 p.

Received 16 April 1991;

Accepted 17 May 1991. 